\title{
Outcome of gestational trophoblastic disease in a rural tertiary centre of Haryana, India
}

\author{
Pinkey Lakra ${ }^{1}$, Vijayata Sangwan ${ }^{1}$, Sunita Siwach $^{1}$, Richa Kansal ${ }^{1}$, Rajiv Mahendru ${ }^{1}$, \\ Anjali Sharma ${ }^{2}$
}

\begin{abstract}
${ }^{1}$ Department of Obstetrics and Gynecology, BPS, GMC, Khanpurkalan Sonipat, Haryana, India
${ }^{2}$ Department of Obstetrics and Gynecology, Srijan Hospital, Allahabad, Uttar Pradesh, India
\end{abstract}

Received: 16 November 2016

Accepted: 03 December 2016

\section{*Correspondence:}

Dr. Pinkey Lakra,

E-mail: drpinki_18@yahoo.com

Copyright: ( ) the author(s), publisher and licensee Medip Academy. This is an open-access article distributed under the terms of the Creative Commons Attribution Non-Commercial License, which permits unrestricted non-commercial use, distribution, and reproduction in any medium, provided the original work is properly cited.

\begin{abstract}
Background: The reported incidence of GTD varies widely worldwide, from a low of 23 per 100,000 pregnancies (Paraguay) to a high of 1,299 per 100,000 pregnancies (Indonesia). The reported incidence of GTD in India is inconsistent therefore we planned to do an analysis of the GTD at our institute which is a referral tertiary center of Haryana.

Methods: Records of patients of GTD admitted from January 2014 to June 2016 were analyzed and incidence per 1000 deliveries was calculated. The demographic profile, clinical presentation, management and complications were studied.

Results: There were 38 patients of GTD with an incidence of 2.3 per 1000 deliveries. Out of 38 patients 33 (86.8\%) were of molar pregnancy and $5(13.16 \%)$ had GTN. Out of 33 molar patients $27(81.8 \%)$ had complete mole and 6 $(18.2 \%)$ had partial mole. All cases of GTN were low risk and received single agent methotrexate based chemotherapy. The mean age was $23.02 \pm 2.96$ years and $47.4 \%$ were primigravida. The mean gestational age of presentation was $13.84 \pm 3.24$ weeks. There were no mortalities and no recurrences. Education in more than half i.e. $57.1 \%$ patients was below primary and 7 of the 19 patients with GTD, who could be followed telephonically, were found to have not followed the contraceptive advice and conceived within 6 months of the treatment of molar pregnancies, 5 had vaginal deliveries of live babies one of which was preterm and rest 2 had spontaneous abortions.

Conclusions: In view of poor reporting from developing countries there is a need for a nodal centre exclusively for GTD in each state. Poor compliance and contraceptive practice due to uneducated population especially in rural India, warrants a need for prophylactic chemotherapy in high risk cases.
\end{abstract}

Keywords: Gestational trophoblastic disease, GTN, GTD, Molar pregnancy, Neoplasia

\section{INTRODUCTION}

Gestational trophoblastic disease (GTD) includes the molar pregnancies which are benign forms with malignant potential and the malignant forms which are collectively known as gestational trophoblastic neoplasia (GTN). Molar pregnancies are either complete mole or a partial mole and GTN includes four pathologic types namely choriocarcinoma, invasive mole, placental site trophoblastic tumour (PSTT) and epitheloid trophoblastic tumor (ETT). The reported incidence of GTD varies widely worldwide, from a low of 23 per 100,000 pregnancies (Paraguay) to a high of 1,299 per 100,000 pregnancies (Indonesia). ${ }^{1}$ The occurrence of a molar pregnancy strongly correlates with maternal age especially for women younger than 16 years and even more pronounced for those above 45 years. Ultrasound and serum $\beta$ hCG play a central role in diagnosis and further follow up. Persistent abnormal vaginal bleeding and plateau or rising serum $\beta$ hCG levels following any pregnancy are suggestive of GTN. All products of conception from nonviable pregnancies must undergo 
histological examination regardless of ultrasound findings. ${ }^{2}$ The need for chemotherapy following a complete mole is $15 \%$ and after a partial mole is $0.5 \%$. The development of postpartum GTN requiring chemotherapy occurs at a rate of $1 / 50000$ births. ${ }^{3}$ Women are assessed before chemotherapy using the FIGO 2000 scoring system. ${ }^{4}$ Women with scores $\leq 6$ are treated with single agent methotrexate or actinomycin $\mathrm{D}$ based chemotherapy and those with score $\geq 7$ are given several cycles of combination chemotherapy. The risk of relapse after chemotherapy is $3 \%$ and mostly occurs in the first year of follow-up. ${ }^{5}$ Therefore, careful $\beta$ hCG monitoring is required and pregnancy should ideally be delayed until beyond this period.

\section{METHODS}

This is a retrospective descriptive study based on medical records of patients of gestational trophoblastic disease admitted over two and a half years, from January 2014 to June 2016 at BPS GMC for women Khanpurkalan Sonepat Haryana. All cases of molar pregnancy were histologically confirmed but diagnosis of GTN was based on serum $\beta$ hCG levels and ultrasonography findings. The demographic profile, clinical presentation, management and complications were studied. Patients were also enquired telephonically to know their present status. Analysis was done using Microsoft excel and percentages, average, standard deviation and range was calculated.

\section{RESULTS}

The incidence of GTD was 2.3 per 1,000 deliveries. There were total 38 patients of gestational trophoblastic disease over a period of two and a half years, out of with $33(86.84 \%)$ had molar pregnancy (27 complete mole and 6 partial mole) and rest $5(13.16 \%)$ had GTN. Out of 5 patients of GTN one was a postpartum case and rest 4 were post molar. Most of the patients belonged to the age group 20-34 $(92.1 \%)$ with average age of $23.02 \pm 2.96$ years (range 18-35). Most of them were nulliparous $(57.4 \%)$ and all belonged to a rural background with only $22.9 \%$ of them educated above primary class. The most common presentation was bleeding per vaginum as in $84.2 \%$ cases and $15.8 \%$ cases were asymptomatic and diagnosed on ultrasonography. The Average period of gestation at the time of presentation was $13.84 \pm 3.24$ weeks (range of 8-23) and average uterine size was $16.26 \pm 6.27$ weeks (range of 6-30). In 54.6\% patients the uterine height was more than the period of gestation and $75.8 \%$ reported after 12 weeks were crossed. The blood group was $\mathrm{A}+$ in $42.1 \%$ patients. The mean hemoglobin was $8.31 \pm 1.5 \mathrm{gm} / \mathrm{dl}$ (range $5-12.2$ ), $87.9 \%$ were anaemic and $57.9 \%$ received one or more units of blood transfusion. Serum $\beta \mathrm{hCG}$ of $18.4 \%$ patients was more than $1,00,000 \mathrm{mIU} / \mathrm{ml}$ and $28.9 \%$ had theca lutein cysts. Only 2 patients of over distended uterus required emergency suction evacuation and rest all were evacuated electively. Three patients had hyperemesis and 4 had hyperthyroidism but no thyrotoxicosis. One patient of GTN was most likely choriocarcinoma as it was following a full term cesarean delivery and histological diagnosis could not be made because dilation and evacuation revealed only blood clots. Remaining 4 patients had history of evacuation of molar pregnancy and had persistent or rising serum $\beta$ hCG levels and their sonography suggested lesions in uterine wall with cystic areas of high velocity low resistance flow most likely invasive mole. They were all referral patients who had repeat evacuations before admission. All GTN patients were low risk non-metastatic and received single agent methotrexate folinic acid rescue chemotherapy for multiple cycles. There were no ICU admissions or mortalities. Telephone numbers of 30 out of 38 patients were retrieved from hospital records, out of which only 19 patients answered to the calls. Out of the nineteen 1 was a patient of invasive mole who conceived after three months of 2 cycles of chemotherapy and delivered a fullterm live and healthy baby. Out of the 17 molar patients six had conceived within six months of the suction evacuation, 4 had live babies and 2 had abortions. Out of the 19 traceable patients only eight had a complete follow up.

Table 1: Demographic profile.

\begin{tabular}{|lll|}
\hline Variable & Numbers & Percentage \\
\hline $\begin{array}{l}\text { Age in years } \\
<20\end{array}$ & 2 & \\
$20-34$ & 35 & $92.1 \%$ \\
$\geq 35$ & 1 & \\
\hline $\begin{array}{l}\text { Parity } \\
\text { primi }\end{array}$ & & \\
0 & 18 & $47.4 \%$ \\
1 & 22 & $57.9 \%$ \\
2 & 9 & $23.7 \%$ \\
$\geq 3$ & 1 & \\
\hline Abortions & 6 & $15.8 \%$ \\
0 & & \\
1 & 33 & $86.8 \%$ \\
2 & 5 & \\
$\geq 3$ & 0 & \\
\hline Religion & 0 & \\
Hindu & & \\
Muslim & 36 & $84.7 \%$ \\
\hline Pain & 2 & $84.2 \%$ \\
\hline Bleeding per vaginum & 32 & $15.8 \%$ \\
\hline Asymptomatic with & 6 & \\
USG diagnosis & & \\
\hline
\end{tabular}

\section{DISCUSSION}

Incidence: Gestational trophoblastic disease has a wide variation worldwide in the incidence based on ethnic and geographic factors. In India there is paucity of data on GTD because of poor record maintenance at the government as well as private health facilities and absence of special centers dedicated to GTD patients. The 
incidence of $\mathrm{H}$. mole is 1 in 1500 in USA, 1 in 1000 in Europe, 2 in 1000 in southeast Asian countries and Japan and 1 in 125 in Taiwan. ${ }^{6,7}$ In our study the incidence of GTD is 2.3 per 1000 deliveries (3 molar pregnancies in 16,522 deliveries and 5 GTN in 16,522 deliveries). The incidence in one Indian study is 1 in 600 and a Pakistani study has incidence of 2.5/1000 deliveries and a Nepalese study has 3.9/1000 deliveries. ${ }^{8.9 .10}$ The incidence of choriocarcinoma is difficult to estimate because of its rarity and trouble in clinically distinguishing postmolar choriocarcinoma from invasive mole owing to lack of histology biopsy material. Although choriocarcinoma has been reported to affect approximately 1 in 40000 to 9 in 40000 pregnancies. ${ }^{11}$ In our study the incidence of choriocarcinoma was 1 in $\sim 16000$ deliveries which is quite high as compared to western countries.

Table 2: Complications.

\begin{tabular}{|lll|}
\hline Complications & Numbers & Percentage \\
\hline Anemia & 29 & $87.9 \%$ \\
\hline Blood transfusion & 22 & $57.9 \%$ \\
\hline Hyperemesis & 3 & $07.9 \%$ \\
\hline Hyperthyroidism & 4 & $10.5 \%$ \\
\hline Theca leutein cysts & 11 & $28.9 \%$ \\
$<6 \mathrm{cms}$ & 5 & $45.5 \%$ \\
$\geq 6 \mathrm{cms}$ & 6 & $54.5 \%$ \\
\hline$\beta-\mathrm{hCG}>100000$ & 7 & $18.4 \%$ \\
mIU/ml & & $13.2 \%$ \\
\hline GTN & 5 & 0 \\
\hline Pre eclampsia & 0 & 0 \\
\hline Mortality & 0 & \\
\hline
\end{tabular}

Table 3: FIGO 2002 modified WHO risk scoring of individual cases of GTN.

\begin{tabular}{|c|c|c|c|c|c|}
\hline & Case 1 & Case 2 & Case 3 & Case 4 & Case 5 \\
\hline Age & 22 & 23 & 24 & 24 & 20 \\
\hline Antecedent pregnancy & $\begin{array}{l}\text { Full-term } \\
\text { cesarean delivery }\end{array}$ & Molar & Molar & Molar & Molar \\
\hline $\begin{array}{l}\text { Interval of presentation } \\
\text { from antecedent } \\
\text { pregnancy }\end{array}$ & 7 weeks & 6weeks & 8 weeks & 7 months & 5 months \\
\hline $\begin{array}{l}\text { B hCG levels on } \\
\text { admission }\end{array}$ & 98,133 & 18,000 & 7,187 & 922 & 2,354 \\
\hline $\begin{array}{l}\text { Ultrasonography } \\
\text { findings }\end{array}$ & $\begin{array}{l}5 \mathrm{~cm} \text { size } \\
\text { echogenic lesion } \\
\text { in endometrial } \\
\text { cavity extending } \\
\text { in myometrium } \\
\text { with loss of } \\
\text { interface }\end{array}$ & $\begin{array}{l}5.3 \mathrm{~cm} \text { lesion } \\
\text { in anterior } \\
\text { wall }\end{array}$ & $\begin{array}{l}3.8 \mathrm{~cm} \text { lesion in } \\
\text { right lateral } \\
\text { myometrium } \\
\text { close to } \\
\text { endometrium } \\
\text { reaching serosa }\end{array}$ & $\begin{array}{l}2.5 \mathrm{~cm} \text { size } \\
\text { lesion in } \\
\text { posterior } \\
\text { myometrium }\end{array}$ & $\begin{array}{l}3 \mathrm{~cm} \text { size } \\
\text { lesion in } \\
\text { anterior wall } \\
\text { of uterus }\end{array}$ \\
\hline Metastasis & Nil & Nil & Nil & Nil & Nil \\
\hline FIGO score & 6 & 5 & 2 & 3 & 3 \\
\hline
\end{tabular}

Demographics: The mean age of GTD in this study was $23.02 \pm 2.96$ years (range 18-35) which is close to the mean age of $24.6 \pm 4.4$ years in another Indian study by Kumar N, whereas in a study from Malaysia the mean age of the women with molar pregnancies was 32.0 \pm 7.9 years which is higher than our group. Early marriage and early conception may be the reason for lower mean age in our study. ${ }^{12,13}$ The occurrence of a molar pregnancy strongly correlates with maternal age especially for women younger than 16 years and even more pronounced for those above 45 years. ${ }^{14}$ But none of our patients belonged to these ages, may be because most of the patients in rural India conceive between 18 to 35 years. Our patients presented at the mean gestational age of $13.84 \pm 3.24$ weeks (range of 8-23) whereas the mean gestational age at initial diagnosis was 11 weeks \pm 3 days in Malaysian study. In the Malaysian study $17.6 \%$ women had a uterus larger than dates the but in our study in $54.6 \%$ patients uterine height was more than the period of gestation and this may be because of late presentation. In our study only $15.8 \%$ were asymptomatic and presented with a sonography report saying molar pregnancy and rest $84.2 \%$ presented with one or the other symptoms and vaginal bleeding happened to be the most common presenting symptom as in all other studies. Most of our patients $(57.4 \%)$ were nulliparous but studies claim that there is no clear relation between gravida and parity and GTD. ${ }^{15,16}$ Although a Nigerian study reports that risk to GTD increases with parity, especially parity four and above. ${ }^{17}$

Anemia happened to be the most common complication as in $87.9 \%$ of the patients and $57.9 \%$ received one or more units of blood transfusion. In a significant number 
of $42.1 \%$ patients the blood group was $\mathrm{A}+$, but the modified WHO scoring of FIGO 2002 has eliminated this as a risk factor. Four patients had hyperthyroidism with raised serum TSH levels but there was no case of thyrotoxicosis. In $18.4 \%$ patients the serum $\beta$ hCG levels were more than $1,00,000 \mathrm{mIU} / \mathrm{ml}$ and $28.9 \%$ had theca lutein cysts which are higher than a Nepalese study having $20.6 \%$ patients with theca lutein cysts, as there are limited places in referral area with reliable recording and reporting done by ultrasonologists according to them. ${ }^{18}$ But all of the sonography in our study was done by consultant radiologists which adds to the difference.

Choriocarcinoma: Only one patient out of 16522 deliveries was a choriocarcinoma although it was not histopatologically proved as the dilation and curettage revealed only blood clots but the high levels of serum $\beta$ hCG close to $100,000 \mathrm{mIU} / \mathrm{ml}$ and being a postpartum event raised the clinical suspicion of choriocarcinoma. After FIGO risk scoring, she was given methotraxate based chemotherapy with folinic acid rescue and had adequate serum $\beta$ hCG fall after 2 cycles and was discharged in stable condition. But she could not be traced telephonically for the present status.

Invasive mole: In our study 2 out of 4 invasive mole patients had one abortion for which they underwent curettage but rest 2 were primigravida. Kumar $\mathrm{N}$ in his study found that repeated abortions and mechanical interference (check curettage) were more common in patients with invasive mole, since $33.3 \%$ of the patients (7 out of 21) had 4 or more abortions, which was significantly higher than in the control group, with $6.3 \%$ of the patients having repeated abortions (411 of 6540, $\mathrm{p}<0.001) .{ }^{11}$ But we observed that all our patients had underwent repeat curettage following molar evacuations which may be a cause for invasion suggesting that repeat curettages after antecedent molar pregnancy also might lead to invasive mole.

Follow up: Telephone numbers were retrieved from hospital records of 30 pateints out of which only 19 patients answered to the calls. Seven of these had conceived and 5 had normal deliveries and 2 aborted. Out of the 19 traceable patients only eight had a complete follow up. In the absence of a nodal centre for registration of GTD there is not only paucity of data but also failure of the medical staff as well as patients to understand the need of regular follow up as even the educated patients fail to come for a follow up with serum $\beta$ hCG levels. They can only be tracked by a registration centre dedicated exclusively for this and reminders can be sent to them. In the UK, there exists an effective registration and treatment programme and it has achieved impressive results, with high cure (98-100\%) and low (5-8\%) chemotherapy rates. ${ }^{19}$

Role of prophylactic chemotherapy: According to a cochrane review the controversial practice of prophylactic chemotherapy to prevent gestational trophoblastic neoplasia in women with molar pregnancy, is not recommended as it does not alter the need for careful monitoring and follow-up of women with hydatidiform moles. ${ }^{20}$ Although the available data shows that prophylactic chemotherapy does reduce the risk of the development of GTN, but the practice also delays diagnosis and treatment of GTN when it does occur and unnecessarily exposes women in whom GTN never develops to toxic adverse effects. However, it can be considered an option for high-risk patients, as in India, who may have compliance issues, and those in settings where tests for serum $\beta$-hCG level determination is not available.

This study has a limitation mainly with the follow up results. Although to the best of our knowledge none of the patients developed any sort of life threatening complications like pulmonary embolism, haemoperitoneum or required ICU admissions and all of them were discharged in a stable condition.

\section{CONCLUSION}

Gestational trophoblastic disease can be treated with nearly $100 \%$ cure rates especially when follow up is adequate. In the developed countries there are registration centres for GTD with aims of monitoring of serum $\beta$ hCG levels following surgical evacuation, provide optimal management of persistent trophoblastic disease and also provide information for patients and medical staff. Similarly there is a strong need to set up such a system in India also so that the patients can be managed and followed properly to avoid complications and better guidelines can be formulated by studying their response to the various chemotherapy agents. Poor compliance and contraceptive practice due to uneducated population especially in rural India, warrants a need for prophylactic chemotherapy in high risk cases although it does not negate the need for follow up.

Funding: No funding sources

Conflict of interest: None declared

Ethical approval: The study was approved by the Institutional Ethics Committee

\section{REFERENCES}

1. Altieri A, Franceschi S, Ferlay J. Epidemiology and aetiology of gestational trophoblastic diseases. Lancet Oncol. 2003;4(11):670-8.

2. Hinshaw K, Fayyad A, Munjuluri P. The managementof early pregnancy loss. In Green-top Guideline. London: Royal College of Obstetricians and Gynaecologists, 2006.

3. Newlands ES. Presentation and management of persistent gestational trophoblastic disease and gestational trophoblastic tumours in the UK. In: Hancock BW, Newlands ES, Berkowitz RS, Cole LA, editors. Gestational Trophoblastic Disease. 3rd 
ed. London: International Society for the Study of Trophoblastic Disease; 2003.p.277-298.

4. International Federation of Obstetrics and Gynecology Oncology Committee. FIGO staging for gestational trophoblastic neoplasia 2000. Int J Gynecol Obstet. 2002;77:285-7.

5. Seckl MJ, Sebire NJ, Fisher RA. Gol fier F, Massuger L, Sessa C, Gestational trophoblastic disease: ESMO Clinical Practice Guidelines for diagnosis, treatment and follow-up. Annals of Oncology. 2013;24(suppl 6):vi39-50.

6. Loukovaara M, Pukkala E, Lehtovirta P, Leminen A. Epidemiology of hydatidiform mole in Finland, 1975 to 2001. Eur J Gynaecol Oncol. 2005;26(2):207-8.

7. Garner EI, Goldstein DP, Feltmate CM, Berkowitz RS. Gestational trophoblastic disease. Clin Obstet Gynecol. 2007;50(1):112-22.

8. Shrivastava S, Gandhewar MR. Gestational trophoblastic disease: a profile of 37 cases. Int J Reprod Contracept Obstet Gynecol. 2014;3(2):31720.

9. Humaira S, Gardezi AI, Qaisrani AR. Incidence of Molar Pregnancies at D. G. Khan Hospital. P J M H S. 2014;8(4):882-4.

10. Koirala A, Khatiwada P, Giri A, Kandel P, Regmi M, Upreti D. The Demographics of Molar Pregnancies in BPKIHS. Kathmandu University Medical Journal. 2011;9(4):298-300.

11. Lurain JR. Gestational trophoblastic disease I: epidemiology, pathology, clinical presentation and diagnosis of gestational trophoblastic disease, and management of hydatidiform mole. Am J Obstet Gynecol. 2010;203(6):531-9.

12. Kumar N, Saxena KY, Rathi AK, Raghunandan C, Kumar P. Host and risk factors for gestational trophoblastic disease: a hospital-based analysis from India. Med Sci Monit. 2003;9(10):CR442-4.
13. Nirmala CK et al. Outcome of molar pregnancies in Malaysia: A tertiary centre experience. The Journal of Obstetrics and Gynaecology. 2013;33(2):191-3.

14. Sekl JM, Newlands ES. Gestational Trophoblastic Tumours. In: Shaw RW, Soutter WP, Stanton SL, editors. Gynecology. 3rd ed. Churchill Livingstone; 2003.p.653-654.

15. Ngan S, Seckl MJ. Gestational trophoblastic neoplasia management: an update. Curr Opin Oncol. 2007;19:486-91.

16. Burger RA, Creasman WT. Gestational Trophoblastic Neoplasia. In: Disaia PJ, Creasman WT, editors. Clinical Gynecology Oncology. 6th ed. Mosby; 2002.p.185-210.

17. Ekpo MD. Hyadatidiform Mole in Nigeria. Journal of Obstretrics and Gynecology. 1990;10:363-6.

18. Agrawal N, Sagtani RA, Budhathoki SS, Pokhare HP. Clinico-epidemiological profile of molar pregnancies in a tertiary care centre of Eastern Nepal: a retrospective review of medical records. Gynecologic Oncology Research and Practice. 2015[cited 4 November 2016];2:9

19. Hancock BW. Differences in management and treatment: a critical appraisal. In: Hancock BW, Newlands ES, Berkowitz RS, Cole LA, editors. Gestational Trophoblastic Disease. 3rd ed. London: International Society for the Study of Trophoblastic Disease; 2003.p.447-59.

20. Fu J, Fang F, Xie L. Prophylactic chemotherapy for hydatidiform mole to prevent gestational trophoblastic neoplasia. Cochrane Database System Rev. 2012;10.

Cite this article as: Lakra P, Sangwan V, Siwach S, Kansal R, Mahendru R, Sharma A. Outcome of gestational trophoblastic disease in a rural tertiary centre of Haryana, India. Int J Reprod Contracept Obstet Gynecol 2017;6:271-5. 